2

3 Selenium Supplementation Protects Trophoblast Cells from

4 Mitochondrial Oxidative Stress.

5

6

Alisha Khera, Jessica J. Vanderlelie, Anthony V. Perkins

7 School of Medical Science, Griffith Health Institute,

8 Griffith University, Gold Coast Campus

9 Southport, Queensland, Australia.

Corresponding author:

Professor Tony Perkins

School of Medical Science,

Griffith University Gold Coast Campus

Parklands Drive, Southport,

QLD, 9726, Australia

17

E-mail: a.perkins@griffith.edu.au

Phone: + 61 (0) 755528818

Fax: + $61(0) 755529081$

Keywords: Trophoblast, Oxidative Stress, Selenium, Reactive Oxygen Species, Antioxidants 
INTRODUCTION: Oxidative stress plays an important role in the pathogenesis of preeclampsia, a placental disorder affecting approximately $7 \%$ of pregnancies. Trophoblast cells are susceptible to oxidative stress which causes increased cell death and placental turnover. In this study, inhibitors of the mitochondrial respiratory chain were utilised to induce oxidative stress and the effect that selenium supplementation had on trophoblast viability was investigated. METHODS: Trophoblast cells (BeWo, JEG-3 and Swan-71) were treated with $\mathrm{Na}$ 
Oxidative stress describes a condition where the presence of reactive oxygen and nitrogen species (RONS) overwhelms cellular antioxidant defences. The initial response to oxidative stress is to up regulate defensive mechanisms such as heat shock proteins and anti-oxidant enzymes. Cells enter a state of suspended animation whilst the stress is counteracted or disperses at which point the cells return to homeostasis. If the oxidative insult persists, oxidised macromolecules such as lipids, proteins and nucleic acids are released. Persistent or excessive oxidative stress will lead to autophagy, apoptosis and necrosis with the associated release of cellular debris [extensively reviewed 1]. Placental oxidative stress is central in the pathogenesis of many disorders of pregnancy including preeclampsia and preterm labour and numerous studies have shown that there is increased shedding of oxidised macromolecules as well as cellular debris from placentae affected by these disorders $[2,3]$.

Anti-oxidant enzymes are central to protecting cells from oxidative stress. These include enzymes involved in the Glutathione and Thioredoxin reducing systems such as Glutathione Peroxidase (GPx) and Thioredoxin Reductase (ThxRed). These two proteins are selenoenzymes, whereby activity in all cells and tissues is dependent upon an adequate supply of the essential micronutrient selenium. This provides an elegant mechanism for up-regulation, as selenium supplementation is able to promote the activity of these proteins in many cell types, in animal studies and in humans $[4,5,6]$.

Previous work from this laboratory proposed that the up-regulation of GPx and ThxRed using selenium supplementation would protect cardiac tissues from the damaging effects of the oxidative stress during clinical procedures including coronary artery bypass grafts. This proved to be the case and in clinical studies the beneficial effects of selenium supplementation, in association with other essential micronutrients, resulted in significantly quicker patient recoveries [7]. The same approach is an attractive proposition when considering placental oxidative stress in complications of pregnancy such as preeclampsia. Could maximising placental expression of these proteins using selenium supplementation protect trophoblast from oxidative stress? 
In a recently published paper we demonstrated that up-regulation of GPx and ThxRed using both inorganic sodium selenite and organic selenomethionine was able to protect trophoblast from exogenously added reactive oxygen species such as peroxides [8]. In the present study we have asked the same question but generated the oxidative stress endogenously by selectively blocking the electron transport chain and generating mitochondrial oxidative stress.

\section{METHODS AND MATERIALS.}

\section{Cell Culture and Reagents:}

The human choriocarcinoma cell lines BeWo and JEG-3 cells were obtained from American Tissue Culture Collection (ATCC). The non-choriocarcinomic trophoblastic cell line Swan-71 was kindly provided by Professor Gil Mor, Yale University. Cells were grown and maintained at $37^{\circ} \mathrm{C}$ with $5 \% \mathrm{CO}_{2}$ in Dulbecco's Modified Eagle Medium (Invitrogen, Australia) containing 10\% fetal bovine serum and $500 \mathrm{U} / \mathrm{mL}$ penicillin-streptomycin (Invitrogen, Australia). Antimycin and Rotenone were obtained from Sigma-Aldrich Ltd, Australia. All other reagents, unless stated otherwise, were obtained from Sigma- Aldrich Ltd, Australia. Trophoblast cells were collected from $75 \mathrm{cc}$ flasks by trypsinization and were seeded in 96 well sterile tissue culture plates at 10,000 cells per well for treatment and analysis.

\section{Cell Extraction:}

To extract protein for biochemical analysis, the confluent monolayer from $75 \mathrm{cc}$ flasks was collected after 24 hours of continuous culture in selenium supplemented media at $100 \mathrm{nM}$ NaSe and $500 \mathrm{nM}$ SeMet. The collected cell pellet was resuspended in $300 \mu \mathrm{L}$ of cell lysis reagent $(50 \mathrm{mM}$ Tris- $\mathrm{HCl}, 150 \mathrm{mM} \mathrm{NaCl}, 1 \%$ Triton and $1 \%$ Tween20) and incubated on ice for $30 \mathrm{~min}$. The lysed cell suspension was centrifuged at $12000 \mathrm{rpm}$ for $5 \mathrm{~min}$ to pellet cell debris and the protein-containing supernatant was removed and stored at $-20^{\circ} \mathrm{C}$ until use.

\section{Protein Estimations:}

Quantification of the protein content from the cell extracts was performed using a BCA Protein Assay kit (Pierce, Rockford, USA) following the manufacturers protocol. Bovine serum albumin (BSA) was used as the protein standard, enabling the 
construction of a standard curve, from which unknown protein concentrations could be extrapolated. Protein concentrations are expressed as $\mathrm{mg}$ of protein per $\mathrm{mL}$ of cell extract $(\mathrm{mg} / \mathrm{mL})$.

\section{Glutathione Peroxidase (GPx) Assay:}

Glutathione Peroxidase activity was quantified using a GPx assay, as first described by Flohe \& Gunzler [9]. Glutathione Peroxidase present in the protein cell extract reduces the hydroperoxide substrate tert-butyl hydrogen peroxide and becomes oxidised. The oxidised GPx is regenerated by glutathione (GSH), which becomes oxidised to glutathione disulphide (GSSG). The GSSG can then be returned to GSH by the donation of two electrons from NADPH via the enzyme glutathione reductase (GR). The rate of decrease of NADPH directly correlates to GPx activity in the cell extract and can be measured spectrophotometrically at 340nm using a Tecan Sunrise plate reader with Magellan software. The activity measured was expressed as milliunits per milligram of protein ( $\mathrm{mU} / \mathrm{mg}$ of protein). The inter assay and intra assay coefficients of variation were $4.43 \%$ and $7.96 \%$ respectively.

\section{Thioredoxin Reductase (ThxRed) Assay:}

A commercial Thioredoxin Reductase assay was used to determine the activity in cells extracts. The kit was purchased from Cayman Chemical Company and $20 \mu \mathrm{L}$ of cell extract was assayed in triplicate. The results were expressed as nmols activity per mg protein. The inter assay and intra assay coefficients of variation were $7.47 \%$ and $7.19 \%$ respectively

\section{Selenium Supplementation and oxidative stress:}

Trophoblast cell number was adjusted to 100,000 cells per $\mathrm{mL}$ and $100 \mu \mathrm{L}$ was added to each well in a 96 well plate and incubated for $24 \mathrm{~h}$ at $37^{\circ} \mathrm{C}$. Cells were then treated with selenium in the form of inorganic sodium selenite (NaSe) or organic selenium methionine (SeMet) prepared in media and added at concentrations of 100 $\mathrm{nM}$ or $500 \mathrm{nM}$ respectively. Cells were further incubated at $37^{\circ} \mathrm{C}$ for $24 \mathrm{~h}$. Trophoblast cells were then oxidatively stressed with various concentrations of Antimycin (40, $80,160,240,340 \mu \mathrm{M})$ and Rotenone $(100,200,400,600,800 \mathrm{nM})$ and incubated for $4 \mathrm{~h}$ at $37^{\circ} \mathrm{C}$ with $5 \% \mathrm{CO}_{2}$. 


\section{Resazurin End Point Assay:}

To assess cellular function the Resazurin end point assay was used. This assay is an oxidation-reduction indicator, detecting the production of NADH/NADPH and assessing the mitochondrial metabolic activity [10]. Resazurin is non-fluorescent until it is reduced to resorfin, which is highly fluorescent. Following treatments as described above the media was removed by vacuum aspiration and cells were washed twice with DPBS. Resazurin (200ul of 40nM) was added to each well followed by a $2 \mathrm{hr}$ incubation. The degree of reduction of resazurin to resorufin was determined by fluorescence (excitation $530 \mathrm{~nm}$; emission $590 \mathrm{~nm}$ ) using a Fluoroskan Ascent microplate fluorometer (Thermo Scientific, Australia).

\section{Statistical Analysis}

Statistical analysis was performed using Graph Pad, PRISM version 5.03 for Windows, GraphPad Software, San Diego California USA, www.graphpad.com. OneWay analysis of variance (ANOVA) with Tukey's Post Hoc testing was used to analyse significant differences between selenium and non-selenium treatment groups of equal $n$ value for all treatment regimes. $P$ values less than 0.05 were considered significant and all data is presented as mean +/- standard deviation. Each experiment was repeated a minimum of three times with all experiments conducted in triplicate.

\section{Results}

Glutathione Peroxidase (GPX) and Thioredoxin Reductase (ThxRed) activity post selenium supplementation

In BeWo cells, the baseline level of GPx activity was $129.6 \pm 15.17 \mathrm{mU} / \mathrm{mg}$ (Fig 1). After the supplementation with NaSe (100nM) or SeMet (500 nM), GPx activity was increased to levels of $283.5 \pm 14.24 \mathrm{mU} / \mathrm{mg}$ and $273.7 \pm 14.49 \mathrm{mU} / \mathrm{mg}$ of protein. In the BeWo cell line ThxRed baseline activity was $18.53 \pm 2.11 \mathrm{mU} / \mathrm{mg}$ of protein. A significant increase $(P<0.05)$ in ThxRed activity was measured for cultures treated with 100nM NaSe $(72.14 \pm 7.34 \mathrm{mU} / \mathrm{mg}$ of protein) and 500nM SeMet (69.52 \pm 5.83 $\mathrm{mU} / \mathrm{mg}$ of protein). Similar significant increases in GPx and ThxRed activity were 
seen in JEG-3 cells, however, although the Swan-71 cells showed an increase level of activity post Se supplementation, it did not reach significance.

\section{Selenium Supplementation Protects from Oxidative Stress induced by Rotenone treatment.}

BeWo, JEG-3 and Swan-71 cell lines were cultured in either media only or supplemented with $100 \mathrm{nM}$ NaSe or $500 \mathrm{nM}$ SeMet to induce GPx and ThxRed activity. Cells were subsequently stressed with increasing doses of Rotenone (100, 200, 400, $800 \mathrm{nM}$ ) and cellular activity determined using the reszaurin end point assay (Fig 2). Significant reductions in cellular activity were observed in cells exposed to all rotenone concentrations $(\mathrm{P}<0.001)$. Prior incubation with NaSe was demonstrated to protect trophoblast cells from oxidative stress at concentrations of $400 \mathrm{nM}(70.99 \% \pm 24.26 ; \mathrm{P}<0.001)$ and $200 \mathrm{nM}(88.56 \% \pm 18.81 ; \mathrm{P}<0.05)$ when compared to unsupplemented control cultures that displayed cellular activities of $36.77 \% \pm 20.19(400 \mathrm{nM})$ and $71.72 \% \pm 26.03(200 \mathrm{nM})$ respectively. Similarly, prior treatment with 500nM SeMet resulted in protection from rotenone-induced stress at concentrations of 400nM (66.92\% \pm 26.20; P<0.001) and 200nM (101.3\% \pm 15.96; $\mathrm{P}<0.05)$. Identical observations were made with JEG-3 and Swan-71 cells.

Selenium Supplementation Protection from Oxidative Stress induced by Antimycin treatment.

BeWo, JEG-3 and Swan-71 cell lines were cultured in either media or supplemented with $100 \mathrm{nM}$ NaSe or $500 \mathrm{nM}$ SeMet and subsequently stressed with increasing doses of Antimycin. Antimycin concentrations of $80 \mu \mathrm{M}$ to $320 \mu \mathrm{M}$, applied for 4 hours, resulted in a dose dependent significant decrease in cellular activity in all three cell types $(P<0.0001)$. As shown in Figure 3a, Swan-71 cells supplemented with NaSe exhibited protection from oxidative stress at Antimycin concentrations of $80 \mu \mathrm{M}$ (86.26\% \pm 16.45 vs. $52.60 \% \pm 23.57 ; \mathrm{P}<0.001), 120 \mu \mathrm{M}$ (75.06\% \pm 9.47 vs. $47.03 \%$ \pm 12.09 ; $\mathrm{P}<0.01), 160 \mu \mathrm{M}(78.16 \% \pm 21.72$ vs. $26.74 \% \pm 21.86 ; \mathrm{P}<0.001)$ and $240 \mu \mathrm{M}$ $(53.74 \% \pm 22.88$ vs. $11.51 \% \pm 9.96 ; \mathrm{P}<0.001)$. Prior treatment with SeMet also resulted in protection from Antimycin induced oxidative stress when exposed to concentrations of $80 \mu \mathrm{M}$ ( $\mathrm{P}<0.01), 120 \mu \mathrm{M}$ ( $\mathrm{P}<0.01), 160 \mu \mathrm{M}(\mathrm{P}<0.001)$ and 240 $\mu \mathrm{M}$ $(P<0.001)$ (Figure 3b). For BeWo and Jeg-3 cell lines, protection against Antimycin 
induced oxidative stress was observed only for the $320 \mu \mathrm{M}-160 \mu \mathrm{M}$ concentration range $(\mathrm{P}<0.001)$.

\section{DISCUSSION}

All aerobic tissues generate reactive oxygen and nitrogen species (RONS) and ample anti-oxidant production is essential for normal homeostasis. Oxidative stress arises when there is an excessive production of (RONS) or there is a diminished capacity of anti-oxidants to negate the detrimental effects of RONS. Typically a tissue experiencing oxidative stress will release evidence of this stress as oxidised lipids, proteins and nucleic acids. Excessive oxidative stress will result in tissue turnover and release of cellular components through apoptotic and necrotic mechanisms [1]. There are numerous reports on the release of oxidised macromolecules from the human placenta and oxidative stress has been proposed as a driver of cellular turnover in this tissue, especially during pathologies such as preeclampsia $[11,12]$.

Glutathione peroxidase (GPx) and Thioredoxin reductase (ThxRed) are selenoproteins and critical components of two very important anti-oxidant systems. Diminished GPx and ThxRed activity results in the generation of oxidative stress demonstrating a causative effect. Furthermore, there is decreased activity of these enzymes in tissues as a consequence of oxidative stress [4,7,11]. As seleno-proteins the expression and activity of GPx and ThxRed is dependent upon an adequate supply of selenium and the level of expression in cells and animal models can be controlled by selenium supplementation. Several reports have suggested that preeclamptic mothers are seleno-deficient and selenium intake may be important in the development of preeclampsia $[4,13,14]$. Hence, the purpose of this study was to investigate the link between selenium supplementation and protecting placental cells from oxidative stress.

Two forms of selenium, organic SeMet and inorganic NaSe were used to up regulate GPx and ThxRed in the trophoblastic cell lines BeWo, JEG-3 and Swan-71. Enzyme assays for GPx and ThxRed were used to confirm the up-regulation of activity postsupplementation. Similar observations have been made in many other cell types and in animal models $[15,16]$. The selenium dependent up-regulation of GPx and 
247 ThxRed was most marked in BeWo and JEG-3 trophoblastic cell lines but less so in Swan-71 cells.

Following induction of anti-oxidant expression, the BeWo, JEG-3 and Swan-71 cells were oxidatively stressed with Rotenone and Antimycin in a dose dependent manner. Rotenone and Antimycin block Complex 1 and 3 respectively of the electron transport chain resulting in electron leakage and generation of superoxide $\left(\mathrm{O}^{*^{-}}\right)$in the mitochondrial matrix. Due to the relatively high concentration and catalytic activity of $\mathrm{Mn}-\mathrm{SOD}$, the $\mathrm{O}^{*^{-}}$is rapidly converted to $\mathrm{H}_{2} \mathrm{O}_{2}$ which is potentially very damaging to cell viability. In these experiments cellular metabolic activity was determined using the Reszaurin end point assay and we investigated whether upregulation of GPx and ThxRed could protect from mitochondrial oxidative stress.

As presented above, there was a dose dependent decrease in the cellular activity in BeWo, JEG-3 and Swan-71 when treated with increasing concentrations of Rotenone (100-800nM) and Antimycin (40-320 $\mu \mathrm{M})$. Prior incubation with Na Selenite or Selenomethionine was able to protect trophoblast cells from oxidative stress. In all trophoblast cell lines there was considerable protection observed at Rotenone concentrations of 400-200nM. Selenium supplementation of Jeg-3 and BeWo cell lines conveyed protection at Antimycin concentrations $120-320 \mu \mathrm{M}$, with protection against Antimycin concentrations as low as $80 \mu \mathrm{M}$ observed in Swan-71 cells. From these observations it would appear that there is a range of stressor concentrations where protection is possible and cells were irreversibly damaged by oxidative stress at higher concentrations. The mechanisms which cause this stress, whether it is lack of respiration, excessive RONS production, apoptosis or necrosis are currently subject to further investigation.

In a previous study we demonstrated that selenium supplementation could protect trophoblast cells from exogenously applied oxidative stress [8]. We used various forms of peroxides to stress cells and clearly demonstrated the beneficial effects of up-regulation of GPx and ThxRed through Se supplementation. However, the concentrations of peroxides used were probably higher than would be present in trophoblast cells in vivo and the application of exogenous peroxides would presumably have more of an effect in the cytoplasm as the cell absorbs the toxin. In 
the present experiment we demonstrated a similar protective effect to endogenously generated oxidative stress. Blocking electron transport with Rotenone and Anyimycin is a generally accepted method of generating intra mitochondrial oxidative stress. This is very pertinent to studies on oxidative stress in the placenta during preeclampsia, which is often attributed to mitochondrial, and or endoplasmic reticulum stress. This study clearly shows a link between selenium, the antioxidant proteins GPx and ThxRed and mitochondrial oxidative stress.

Selenium is an essential micronutrient and without it tissues are susceptible to oxidative stress through loss of function of key enzymes such as GPx and ThxRed [13]. Selenium supplementation also offers an attractive method of maximising antioxidant expression in preparation of an oxidative insult [17]. Our previous work in cardiac tissues has shown the benefits of selenium supplementation in patients undergoing coronary by-pass surgery, a clinical scenario where oxidative stress negatively impacts on cardiac recovery [6]. Similarly, selenium supplementation may be of benefit for women who may experience preeclampsia. Indeed our recent work would suggest a link between selenium status and the development of preeclampsia and recent supplementation trials have indicated a possible beneficial effect $[14,18]$. Larger more controlled trials are needed to prove the benefits of selenium supplementation in lowering the incidence or severity of preeclampsia but it is now clear that selenium, through up-regulation of key anti-oxidant proteins can protect against mitochondrial oxidative stress in placental trophoblast cells.

\section{REFERENCES.}

[1] Halliwell, B \& Gutteridge, J. Free Radicals in Biology and Medicine. $4^{\text {th }}$ Edition 2007. Oxford University Press.

[2] Burton G.J., Jauniaux E, (2011) Oxidative stress. Best Practice \& Research Clinical Obstetrics and Gynaecology 25 (2011) 287-299.

[3] Rusterholz C, Messerli M, Hoesli I, Hahn S. (2011) Placental microparticles, DNA, and RNA in preeclampsia. Hypertens Pregnancy; 30(3):364-75.

[4] Mistry HD, Wilson V, Ramsay MM, Symonds ME, Broughton Pipkin F. (2008) Reduced Selenium Concentrations and Glutathione Peroxidase Activity in Preeclamptic Pregnancies. Hypertension. 2008; 52(5): 881-8.

[5] Vanderlelie J, Venardos K, Perkins AV. (2004) Selenium deficiency as a model of experimental pre-eclampsia in rats. Reproduction. 2004 Nov;128(5):635-41. 
[6] Tanguy S, Grauzam S, de Leiris J, Boucher F. (2012) Impact of dietary selenium intake on cardiac health: experimental approaches and human studies. Mol Nutr Food Res. ;56(7):1106-21

[7] Leong, J.Y., van der Merwe,J., Pepe,S., Bailey,M., Perkins,A.V., Lymbury,R., Esmore,D., Marasco,S., Rosenfeldt,F. (2010) Perioperative metabolic therapy improves redox status and outcomes in cardiac surgery patients: a randomized trial. Heart Lung and Circulation, Volume 19, Issue 10, Pages 584-591

[8] Watson $\underline{M}$, van Leer $\mathrm{L}, \underline{\text { Vanderlelie JJ}}$, Perkins AV.(2012) Selenium supplementation protects trophoblast cells from oxidative stress. Placenta. 2012 Oct 10. pii: S0143-4004(12)00361-X. doi: 10.1016/j.placenta.2012.09.014.

[9] Flohé L, Günzler WA.(1984) Assays of glutathione peroxidase. Methods Enzymol. 1984;105:114-21.

[10] Anoopkumar-Dukie S, Carey JB, Conere T, O'sullivan E, van Pelt FN, Allshire A. (2005) Resazurin assay of radiation response in cultured cells. Br J Radiol. 2005 Oct;78(934):945-7.

[11] Patil SB, Kodliwadmath MV, Kodliwadmath SM.(2007) Role of lipid peroxidation and enzymatic antioxidants in pregnancy-induced hypertension. Clin Exp Obstet Gynecol. 2007;34(4):239-41

[12] Burton GJ, Jones CJ.(2009) Syncytial knots, sprouts, apoptosis, and trophoblast deportation from the human placenta. Taiwan J Obstet Gynecol. 48(1):28-37.

[13] Rayman MP, Bode P, Redman CW. (2003) Low selenium status is associated with the occurrence of the pregnancy disease preeclampsia in women from the United Kingdom. Am J Obstet Gynecol. 2003 189(5):1343-9.

[14] Vanderlelie, J.J., Perkins A.V., (2011) Selenium and Preeclampsia; A Global Perspective. Pregnancy Hypertension 1, 213-224.

[15] Baliga MS, Wang H, Zhuo P, Schwartz JL, Diamond AM. (2007) Selenium and GPx-1 overexpression protect mammalian cells against UV-induced DNA damage. Biol Trace Elem Res. 115(3):227-42.

[16] Akil M, Gurbuz U, Bicer M, Sivrikaya A, Mogulkoc R, Baltaci AK. (2011) Effect of selenium supplementation on lipid peroxidation, antioxidant enzymes, and lactate levels in rats immediately after acute swimming exercise. Biol Trace Elem Res. 2011 Sep;142(3):651-9.

[17] Munaza Riaz, Khawaja Tahir Mehmood. (2012) Selenium in human health and disease : A review. JPMI Vol 26, No 2.

[18] Tara F, Maamouri G, Rayman MP, Ghayour-Mobarhan M, Sahebkar A, Yazarlu O, Ouladan S, Tavallaie S, Azimi-Nezhad M, Shakeri MT, Boskabadi H, Oladi M, Sangani MT, Razavi BS, Ferns G. (2010). Selenium supplementation and the incidence of preeclampsia in pregnant Iranian women: a randomized, double-blind, placebo-controlled pilot trial. Taiwan J Obstet Gynecol. 2010 Jun;49(2 


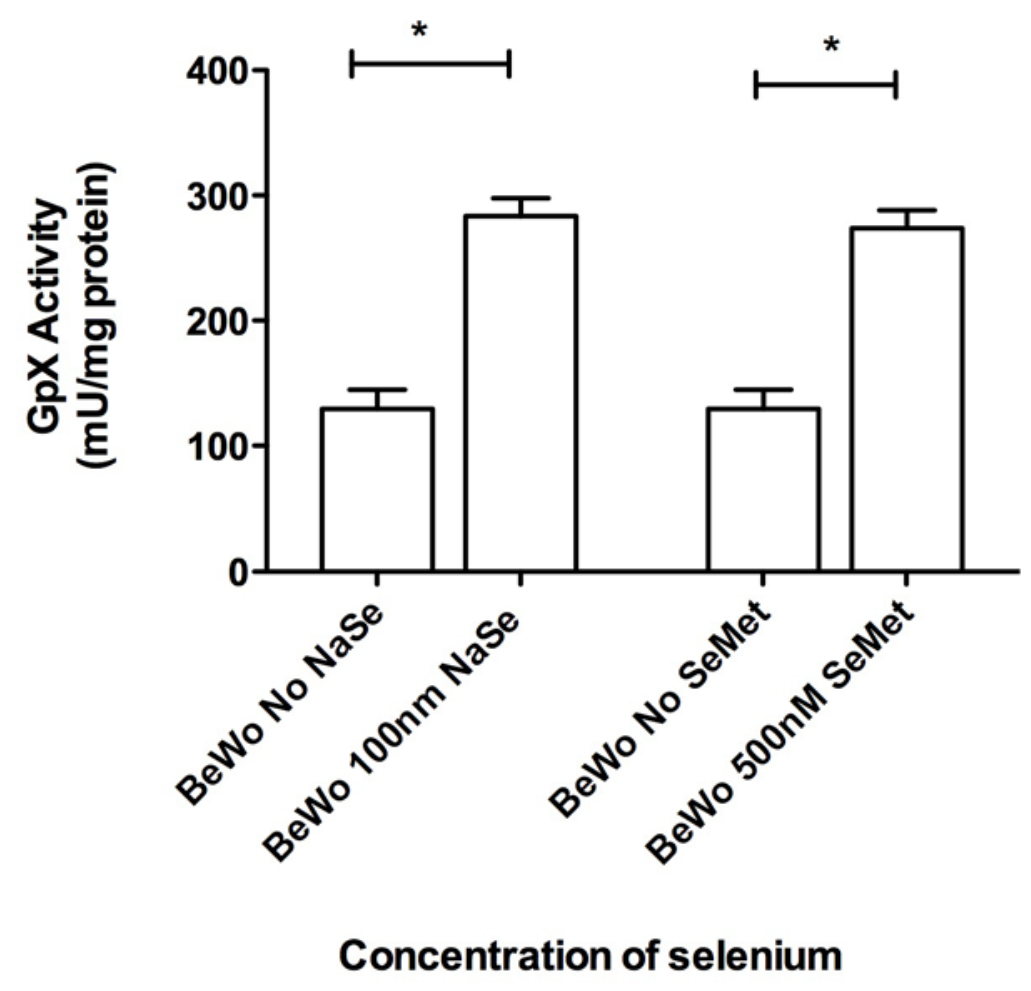

359

360 Figure 1: Activity of GPx in NaSe and SeMet supplemented BeWo cell lines. Values are 361 presented as mean \pm standard deviation (SD). Significant differences were detected 362 between control and maximum activity in the 100nM NaSe and 500nM SeMet supplemented 363 cell lines $\left({ }^{*} p<0.05 n=3\right)$. 


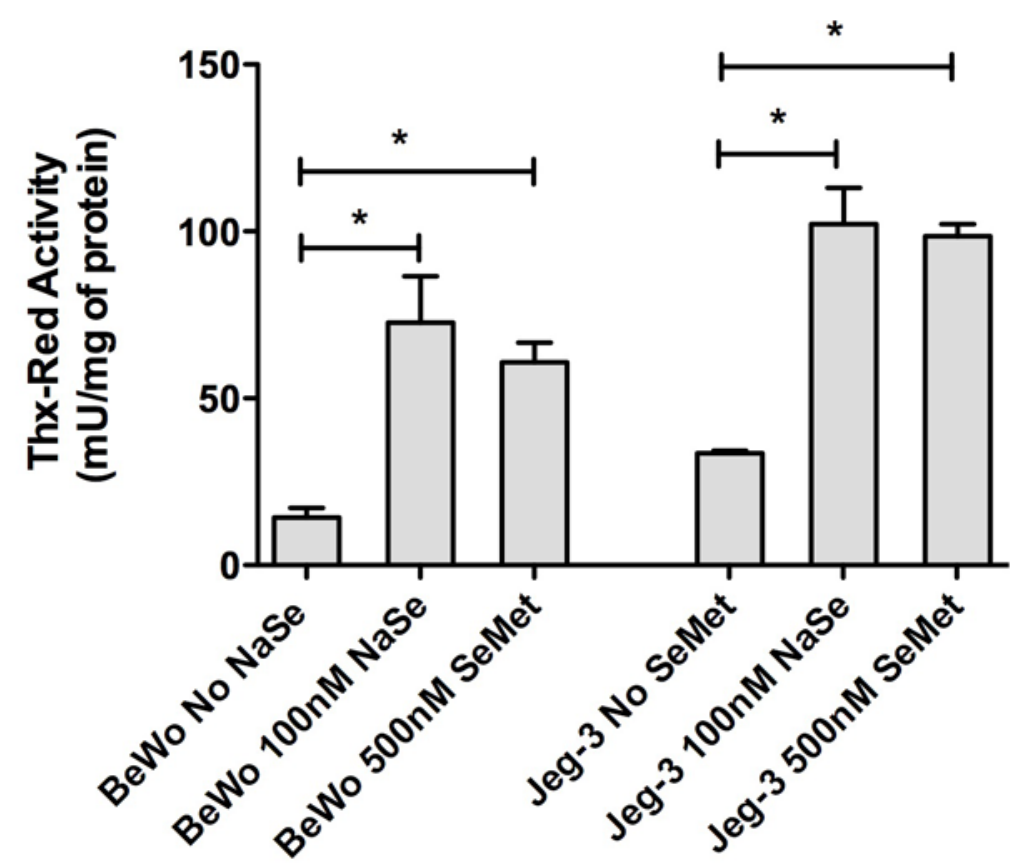

366

367 Figure 2: Activity of Thx-Red in NaSe and SeMet Supplemented BeWo and JEG-3 cell 368 lines; quantified using Thx-Red inhibition assays. Values are presented as mean \pm standard 369 deviation (SD). Significant differences were detected between control and maximum activity 370 in the 100nM NaSe and 500nM SeMet supplemented cell lines ( ${ }^{*} p<0.05, n=3$ ). 

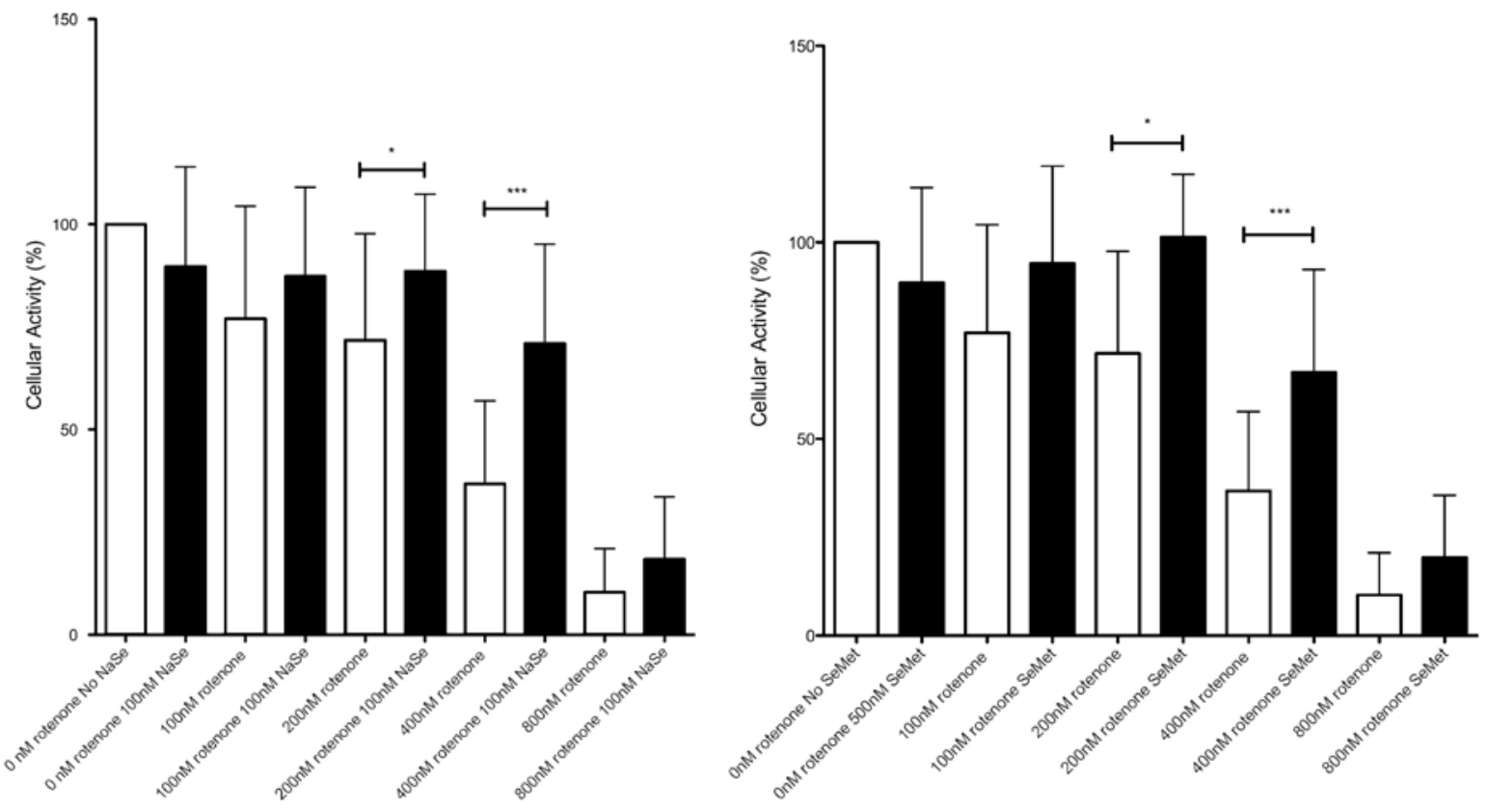

374 Figure 3. Bewo trophoblast cells treated with NaSe (a) or SeMet (b) for $24 \mathrm{hrs}$ and 375 subsequently treated with increasing concentrations of rotenone. Values are presented 376 as mean \pm standard deviation (SD) for each group. Significant differences were detected 377 between unsupplemented and NaSe and SeMet supplemented cell lines when treated with $200 \mathrm{nM}$ and $400 \mathrm{nM}$ concentrations of rotenone $\left({ }^{\star} p<0.05,{ }^{\star \star *} \mathrm{p}<0.001, \mathrm{n}=9\right)$. 

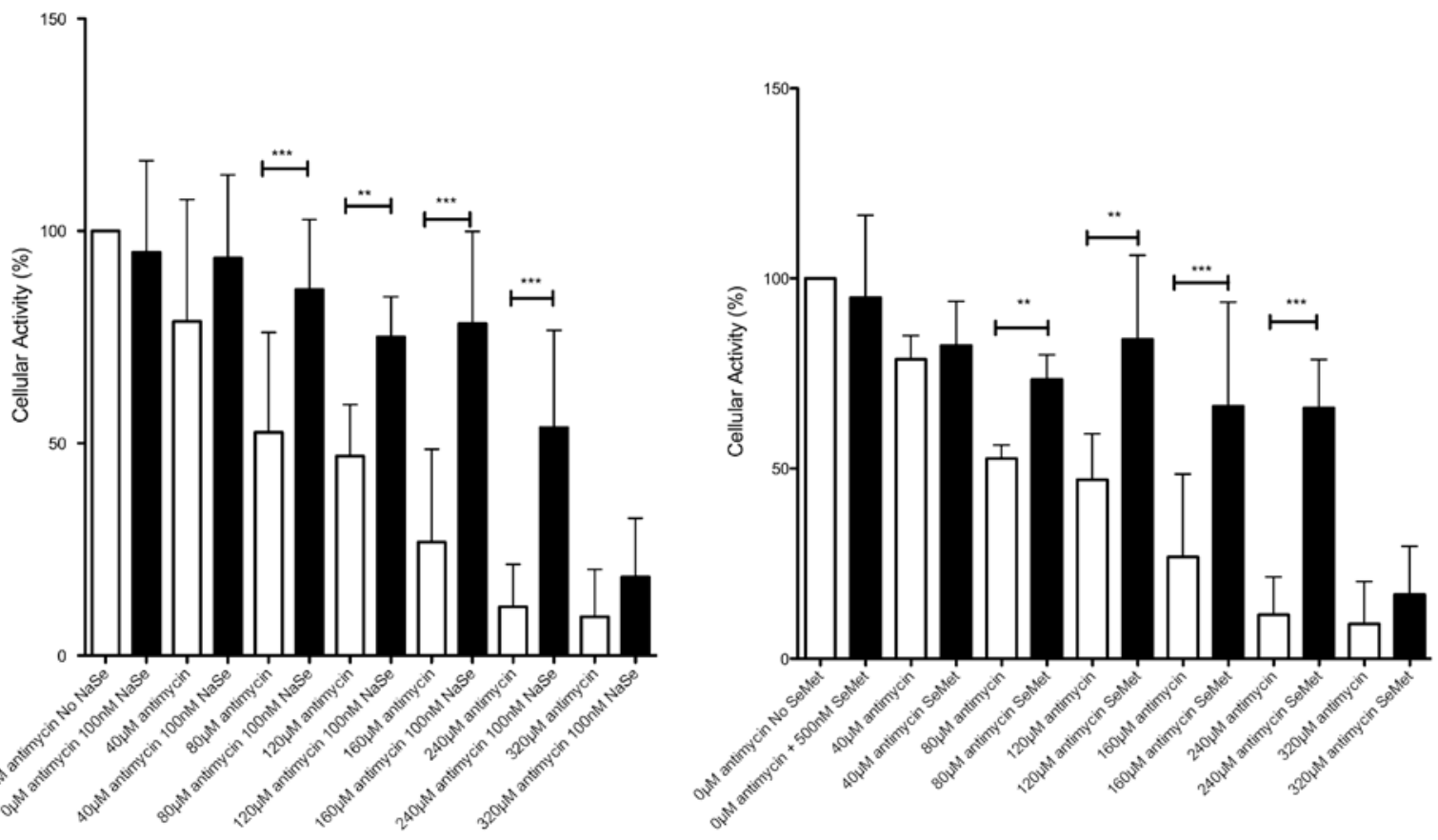

382 Figure 4: Swan-71 trophoblast cells treated with NaSe (A) or SeMet (B) for 24hrs and subsequently treated with increasing concentrations of antimycin. Values are presented as mean \pm standard deviation (SD) for each group. Significant differences were detected between unsupplemented and NaSe and SeMet supplemented cell lines when treated with $80-240 \mu \mathrm{M}$ concentrations of antimycin $\left({ }^{\star *} p<0.01\right.$, ${ }^{* \star} \mathrm{p}<0.001 \mathrm{n}=9$ ). 